\title{
Investigation into the Heat of Hydration and Alkali Silica Reactivity of Sustainable Ultrahigh Strength Concrete with Foundry Sand
}

\author{
Federico Aguayo, Anthony Torres, Tate Talamini, and Kevin Whaley \\ Department of Engineering Technology, Texas State University, San Marcos, TX, USA \\ Correspondence should be addressed to Federico Aguayo; fred.aguayo@txstate.edu
}

Received 31 March 2017; Accepted 10 May 2017; Published 2 July 2017

Academic Editor: Yao Luan

Copyright (C) 2017 Federico Aguayo et al. This is an open access article distributed under the Creative Commons Attribution License, which permits unrestricted use, distribution, and reproduction in any medium, provided the original work is properly cited.

\begin{abstract}
This study presents the hydration reactivity and alkali silica reaction (ASR) of ultrahigh strength concrete (UHSC) that has been made more sustainable by using spent foundry sand. Spent foundry sand not only is sustainable but has supplementary cementitious material (SCM) characteristics. Two series of UHSC mixtures were prepared using a nonreactive and reactive sand (in terms of ASR) to investigate both the impact of a more reactive aggregate and the use of spent foundry sand. Conduction calorimetry was used to monitor the heat of hydration maintained under isothermal conditions, while ASR was investigated using the accelerated mortar bar test (AMBT). Additionally, the compressive strengths were measured for both series of mixtures at 7, 14, and 28 days to confirm high strength requirements. The compressive strengths ranged from $85 \mathrm{MPa}(12,345 \mathrm{psi})$ to $181.78 \mathrm{MPa}$ (26,365 psi). This result demonstrates that a UHSC mixture was produced. The calorimetry results revealed a slight acceleration in the heat of hydration flow curve compared to the control from both aggregates indicating increased hydration reactivity from the addition of foundry waste. The combination of foundry sand and reactive sand was found to increase ASR reactivity with increasing additions of foundry sand up to $30 \%$ replacement.
\end{abstract}

\section{Introduction}

The challenges facing the concrete industry in the 21st century are greater than ever due to familiar problems such as various durability issues plaguing our infrastructure and their associated life-cycle impacts. These issues, coupled with increasing stringent environmental regulations, have resulted in the need of a sustainable ultrahigh strength concrete (UHSC) that can achieve the goal of safer, durable, and more environmentally-friendly infrastructure. For instance, more effective utilization of locally available industrial wastes/byproducts in concrete such as foundry sand, fly ash, and slag can impart enhanced fresh and hardened properties to concrete, while significantly reducing the disposal volume of these materials. Given the fact that concrete is the most widely used man-made building material in the world, there is an opportunity for significant economical savings and environmental benefits from increased incorporation of waste material in concrete.

The American Concrete Institute (ACI) has defined UHSC as a concrete meeting high strength that cannot always be achieved routinely, using conventional constituents and normal mixing, placing, and curing practice [1]. In the 1950s, concrete with compressive strength of $34 \mathrm{MPa}$ (5000 psi) was considered high strength [1]. Today, high strength concrete is defined as concrete with specified compressive strength of $55 \mathrm{MPa}(8000 \mathrm{psi})$ or higher [1]. In many markets today, concrete having specified compressive strength in excess of $69 \mathrm{MPa}(10,000 \mathrm{psi})$ is routinely produced on a daily basis [1] UHSC itself is considered a sustainable construction building material due to the high requirement of silica fume and fly ash, both of which are waste products from other industries, which provides beneficial mechanical and durability properties for concrete [1]. Not only does UHSC utilize a high 
percentage of fly ash and/or silica fume, the high strength requirement results in higher specific strength of the material. The specific strength of a material is the ratio of the strength to its density [1]. The density of conventional concrete and UHSC is relatively the same, but the strength significantly increases with UHSC; therefore the specific strength is much higher. This fact impacts sustainable construction through decreased transportation cost and emissions as thinner structural elements can be produced out of UHSC, which will require less fuel and produce less carbon emissions during transportation.

Spent foundry sand (FS) is a by-product of ferrous and nonferrous metal casting industries primarily consisting of high quality silica sand with uniform physical characteristics. Approximately 6-10 million tons of this waste is produced annually by the foundry industry in the U.S. alone. Spent foundry sand, when used as partial replacement of fine aggregate in concrete, has been shown to improve the mechanical properties of concrete [2-5]. Existing studies, however, limit their focus to conventional concrete and few report on the inherent durability and hydration properties of these sustainable mixtures.

Alkali silica reaction (ASR) has been one of the most destructive distress mechanisms dominating our infrastructure for several decades. The reaction occurs due to the high $\mathrm{pH}$ of the concrete pore solution as a result of the alkalis from the cementitious material. This aggressive solution attacks certain siliceous minerals found in coarse and fine aggregates that may result in a hydrophilic gel that absorbs water causing abnormal expansion. This expansion can lead to excessive cracking, often resulting in a reduction in the service life of affected structures. Since FS is highly siliceous, ASR expansion can be accelerated from the addition of FS in the mixture.

In the present research, multiple UHSC mixtures with locally available foundry sand were produced and analyzed for their hydration and alkali silica reactivity. Two control UHSC mixtures were developed based on a literature survey and bench line strength. One control used manufactured sand as the sole aggregate, which is a commonly used fine aggregate and typically not reactive (in terms of ASR). In order to assess the impact of foundry waste on the reactivity sequestration of UHSC mixtures, a second control mixture was developed that consisted of reactive sand as the sole aggregate. Foundry sand was then used to partially replace the fine aggregate in the control mixtures in 10, 20, and $30 \%$ by volume increments and their strength, hydration, and ASR performance were compared to the control values.

\section{Literature Review}

2.1. Background Information. UHSC, like conventional concrete, can have a broad range of designs. Most UHSC are being designed without coarse aggregate, or coarse aggregate that is $\leq 9.5-\mathrm{mm}(0.375-\mathrm{in}$.) [1]. In the case that coarse aggregate is omitted, fine aggregate is the sole aggregate in the mixtures, which makes for a more homogenous mixture. Most UHSC mixtures also contain supplemental cementitious materials (SCMs) such as silica fume, fly ash, granulated ground blast furnace slag (GGBFS), and quartz powder, fibers, and high range water reducing admixture (HRWRA). When used in optimum dosages, the HRWRA reduces the water-to-cement (or water-to-cementitious) ratio while improving the workability (viscosity) of the concrete. The addition of the SCMs enhances the mechanical properties of the cement paste by producing secondary hydrates, filling voids, and enhancing rheology $[6,7]$. Due to the burgeoning large structure industry, there are more and more requirements for higher strength concrete. UHSC has been in development since the mid 1950s and many researchers are still investigating the optimum and most efficient manner to produce this material [2]. However, modern construction practices are moving towards sustainable construction through lower cost and sustainable materials; therefore, UHSC improvements should also be focused on becoming more sustainable and more affordable.

In recent years, there has been extensive research conducted to study the effect of FS in concrete production. Fiore and Zanetti [8] categorized the various ways and means of reusing foundry waste. The research conducted by the authors describes the potential for using spent foundry sand from molds in concrete. The focus of the study by Fiore and Zanetti [8] is to describe the potential that foundry sand possesses to ultimately benefit concrete construction materials. The authors begin by describing the particle size of spent foundry sand and the specific size range recommended for concrete. The authors comment that the foundry sand fraction between $0.1 \mathrm{~mm}$ and $0.0025 \mathrm{~mm}(0.0039$-in and 9.84E - 9-in.) can be used as an SCM and any particle size larger than that can be used as fine aggregate in the production of concrete. The authors then focus on the chemical nature of foundry sand and its suitability in concrete. Concrete manufacturers generally require that the chemical percentage of cement be approximately $65 \% \mathrm{CaO}, 25 \% \mathrm{SiO}_{2}, 4-10 \% \mathrm{Al}_{2} \mathrm{O}_{3}$, and $1-3 \% \mathrm{Fe}_{2} \mathrm{O}_{3}$ [8]. Therefore, Fiore and Zanetti [8] conducted a chemical test on foundry sand and the results showed there was over $95 \% \mathrm{SiO}_{2}$ in all samples and due to the high silica content and its inert and fine particulate nature, foundry sand is suitable in concrete as either an SCM or a fine aggregate replacement.

Ganesh Prabhu et al. [9] experimented on the use of FS in lieu of fine particulate aggregates in the production of concrete. Density, slump cone, split tensile strength, flexural strength, and compressive strength tests were used in ascertaining the effect of FS in concrete. Five different concrete mixtures with and without foundry sand (control sample) were prepared. Those five sample mixtures were at $10 \%$, $20 \%, 30 \%, 40 \%$, and $50 \%$ FS replacement levels. The authors also used blue-gray sandstone as coarse aggregate and fine sand sourced from the bank of rivers as fine aggregates. The foundry sand had a specific gravity value of 2.24 and density of $1576 \mathrm{~kg} / \mathrm{m}^{3}$. Test results also showed that FS had water absorption value $(1.13 \%)$, which is considered to be higher than normal. This can be attributed to the ash and wood contents of the foundry sand. Grain size distribution analysis conducted via sieve analysis showed that $8 \%$ of the FS is less than $75 \mu \mathrm{m}$. According to stipulated standards (IS 2720), this 
is a satisfactory equivalency value for fine aggregates size. The compressive strength test was carried out at curing ages of $7,28,90$, and 180 days. The authors also evaluated splitting tensile and flexural strength at 28, 90, and 180 days. A slump cone test was used in analyzing the workability of the concrete mixtures. This was conducted at initial time of 0 minutes and duration/interval of 30 and 60 minutes. The results show that an increase in the replacement level of FS negatively impacts the workability of concrete. This is because water absorption increases with an incremental change in FS proportion. Increase in water absorption also has a direct correlation with the fineness of foundry sand. Alternatively, the authors also postulated that the high absorption properties could possibly be attributed to the ash and clay content of FS. However, the results also show negative impact on the workability of the concrete mixture is insignificant at $10 \%$ replacement level. The authors postulated that a modification of water quantity could potentially counteract the slump loss attributed from the fineness of FS and its ash and clayey content. The authors were able to experimentally show that, in all ages of curing, there was a consistent decrease in compressive strength. However, the compressive test result also showed that the sample mix with $20 \%$ FS has compressive strength value that is similar to that of the control mix. The authors postulated that the reduction of the specific gravity of the concrete due to its ash and clay content might explain the resultant reduction in compressive strength. The flexural strength and splitting tensile strengths results were also similar to the compressive strength results. This shows a marginally incremental change in flexural strength, with progression in the age of curing. However, there was no remarkable enhancement in flexural strength for all tested samples. Once again the only exception is with the concrete mixture of $20 \%$ FS replacement level, which showed a distinct similarity in flexural strength as the control mix. The splitting tensile strength result shows that high replacement proportion $(40 \%, 50 \%)$ will enormously decrease the tensile strength of concrete. The authors concluded that the fineness and impurity of FS are underlying factors that impact the compressive, flexural, and tensile strength of a concrete mix with FS as replacement for fine aggregates. However, appropriately determining the right proportion (20\%) will inevitably counteract any negative impact on the mechanical properties of a concrete mix.

Siddique et al. [2] have shown the potential of using FS in the production of concrete. Their experimental investigation showed how different replacement levels of FS as fine aggregate affect the mechanical properties of concrete. The mechanical properties investigated are compressive strength, splitting tensile strength, flexural strength, and modulus of elasticity. The values of the investigated properties were determined at different ages of concrete samples ( 28 days, 56 days, 91 days, and 365 days). The authors categorized their experiment at 3 replacement level percentages (10\%, 20\%, and $30 \%)$. Based on binder system content, FS can be classified into clay bonded FS, otherwise known as green sand, and chemically bonded FS. This classification is centered on physical and environmental factors. Previous researches have also shown that the naturally occurring components such as high quality silica sand (85-95\%), bentonite clay (4-10\%), and carbonaceous additive (4-10\%) make clay bonded FS ideal for use as replacement material. This is largely because of high silica content and also the adhesive properties and fine particulate nature of its clayey content. The locally sourced FS was also chemically tested as per standards specified by IS 383-1970. Physical analysis shows that FS used has lower unit weight and fineness modulus, in comparison to Portland cement. Siddique et al. [2] also used locally sourced coarse aggregates of $10 \mathrm{~mm}$ and $20 \mathrm{~mm}$ gradation as per IS: $383-1970$ 23 standards. Melamine-based superplasticizers were used in the mixing and preparation of all tested samples. The authors prepared four different concrete mixtures. Three of the mixtures were of $10 \%, 20 \%$, and $30 \%$ FS percentage weight. All concrete samples were stored at $23^{\circ} \mathrm{C}$ temperature to minimize loss of moisture, demolded after 24 hours, and then put in a water-curing tank. The authors investigated properties such as slump, unit weight, temperature, and air content as stipulated by Indian Standard Specifications IS: 1199-1959. The results showed that all specimens attained a marginally significant increase in compressive strength at 28 days of curing. The control mixture showed compressive strength value of $28.5 \mathrm{MPa}$. The other test samples (20\% and $30 \%)$ had compressive strength values of $30.0 \mathrm{MPa}$ and $31.3 \mathrm{MPa}$, respectively. Quantitatively, test samples of $20 \%$ replacement and $30 \%$ replacement showed compressive strength increases of $5.2 \%$ and $9.8 \%$, respectively. All tested concrete mixtures showed increases in compressive strength that is directly proportional to curing age. The consistency in the results of all tested concrete mixtures showed that FS can positively impact the compressive strength of concrete. The authors postulated that this could be attributed to the fineness of FS. Splitting tensile strength, flexural strength, and elasticity modulus test result showed a lot of similarity to the compressive strength result. At 28 days of curing, concrete mixtures of $0 \%, 10 \%, 20 \%$, and $30 \%$ replacement showed splitting tensile strength values of $2.75 \mathrm{MPa}, 2.85 \mathrm{MPa}, 2.9 \mathrm{MPa}$, and $3.0 \mathrm{MPa}$, respectively. Concrete mixtures of $0 \%, 10 \%, 20 \%$, and $30 \%$ replacement achieved flexural strength of $3.41 \mathrm{MPa}, 4.0 \mathrm{MPa}$, $4.1 \mathrm{MPa}$, and $4.18 \mathrm{MPa}$, respectively. Lastly, the concrete mixtures of $0 \%, 10 \%, 20 \%$, and $30 \%$ replacement showed modulus of elasticity values of $25.1 \mathrm{GPa}, 26.75 \mathrm{GPa}, 27.60 \mathrm{GPa}$, and $28.4 \mathrm{GPa}$. This marginal increase in tensile strength and flexural strength was directly proportional to increase in curing age. The authors were able to experimentally show that an increase in FS as replacement for fine aggregate has a positive impact on the mechanical properties of concrete.

Mohammed Viquaruddin and Abdullah Mohammed [10] were able to show the impact of foundry sand on the mechanical and durability properties of concrete. The authors studied the intrinsic physical effects of foundry sand when used as partial replacement material. The mechanical properties studied were compressive strength, split tensile strength, and flexural strength. The tested samples were categorized according to percentage weight $(0 \%, 10 \%, 20 \%, 30 \%, 40 \%$, $50 \%, 60 \%, 70 \%, 80 \%, 90 \%$, and $100 \%)$ of foundry sand used as replacement material. The authors carried out an all-encompassing analysis that ranged from partial to total percentage replacement. Previous researches enunciated by the authors show a definitive pattern of the impact of FS 
TABLE 1: Chemical and mineral composition of cement and silica fume.

\begin{tabular}{lcc}
\hline Compound & Cement & Silica fume \\
\hline $\mathrm{SiO}_{2}$ & $20.23 \%$ & $95.8 \%$ \\
$\mathrm{Al}_{2} \mathrm{O}_{3}$ & $5.79 \%$ & $0.18 \%$ \\
$\mathrm{Fe}_{2} \mathrm{O}_{3}$ & $1.97 \%$ & $0.19 \%$ \\
$\mathrm{CaO}$ & $62.02 \%$ & $0.30 \%$ \\
$\mathrm{~K}_{2} \mathrm{O}$ & $\mathrm{NA}$ & $0.29 \%$ \\
$\mathrm{Na}_{2} \mathrm{O}$ & $0.77 \%$ (equiv.) & $0.20 \%$ \\
$\mathrm{MgO}$ & $1.4 \%$ & $0.20 \%$ \\
$\mathrm{SO}_{3}$ & $3.3 \%$ & $0.11 \%$ \\
\hline
\end{tabular}

on concrete. This established postulation is centered on experiments buffering the notion that FS positively impacts the mechanical properties of concrete. However, some results have also shown that, above or below a particular percentage replacement value $(20 \%)$, there is a reduction in strength performance and density of concrete mixtures tested. The authors postulated that this could be because of the increased water absorption ratio of the concrete mixture with percentage weight of FS. Mohammed Viquaruddin and Abdullah Mohammed [10] also investigated the absorptivity, initial surface absorption, and water absorption properties of all concrete samples tested. The results showed that increase in FS negatively impacted the workability of all tested concrete mixes. The results also showed a consistent increase in the compressive strength of concrete mixture samples up to $90 \%$ FS replacement level. However, concrete samples with $100 \%$ FS replacement showed a decrease in compressive strength. The concrete samples also showed increase in splitting tensile strength up to $70 \%$ FS replacement level. However, other samples showed reduced split tensile strength. Optimum split tensile strength was achieved at $40 \%$ FS replacement. The results also showed that increased age of curing positively impacts split tensile strength of all tested samples. All tested samples exhibited an increase in flexural strength with the exception of concrete mixture samples with FS replacement value more than 50\%. The duration of curing also enhanced the flexural strength of all tested concrete samples.

\section{Experimental Program}

3.1. Cementing Materials. A single ASTM C150 [11] Type I/II ordinary Portland cement (OPC) clinker produced locally was used as a part of this study. The cement has been used extensively within this lab as a control binder for various studies; therefore, the long-term performance of this material is well documented and understood. The total alkali equivalent $\left(\mathrm{Na}_{2} \mathrm{O}_{\mathrm{eq}}\right)$ for this cement is $0.77 \%$. Additionally, a densified silica fume was used at a $25 \%$ replacement by mass of cement in order to produce the UHSC requirements ( $\geq 70 \mathrm{MPa}$ [10 ksi]) [1]. The silica fume used in this study conformed to ASTM C1240 [12] standards. The chemical and physical properties of the cementing materials are given in Table 1.
TABLE 2: Mineral composition of foundry sand.

\begin{tabular}{lc}
\hline Compound & Foundry sand \\
\hline $\mathrm{MgO}$ & 0 \\
$\mathrm{Al}_{2} \mathrm{O}_{3}$ & 1.7 \\
$\mathrm{SiO}_{2}$ & 94.1 \\
$\mathrm{~K}_{2} \mathrm{O}$ & 0 \\
$\mathrm{P}_{2} \mathrm{O}_{5}$ & 0 \\
$\mathrm{CaO}$ & 0.2 \\
$\mathrm{TiO}_{2}$ & 0 \\
$\mathrm{MnO}$ & 0 \\
$\mathrm{Fe}_{2} \mathrm{O}_{3}$ & 5.8 \\
\hline
\end{tabular}

TABLE 3: Grain size distribution for the sand.

\begin{tabular}{|c|c|c|}
\hline Sieve number & Sieve size, $\mathrm{mm}$ (in.) & Percentage passing \\
\hline \multicolumn{3}{|c|}{ Manufactured sand } \\
\hline 30 & $0.60(0.0236)$ & 98.19 \\
\hline 50 & $0.30(0.0118)$ & 34.45 \\
\hline 100 & $0.15(.00591)$ & 3.14 \\
\hline \multicolumn{3}{|c|}{ Reactive sand } \\
\hline 30 & $0.60(0.0236)$ & 98.39 \\
\hline 50 & $0.30(0.0118)$ & 20.4 \\
\hline 100 & $0.15(.00591)$ & 3.5 \\
\hline \multicolumn{3}{|c|}{ Foundry sand } \\
\hline 30 & $0.60(0.0236)$ & 98.59 \\
\hline 50 & $0.30(0.0118)$ & 34.81 \\
\hline 100 & $0.15(.00591)$ & 4.24 \\
\hline
\end{tabular}

3.2. Aggregates. A reactive (siliceous) and a nonreactive (manufactured limestone) fine aggregate were used as a part of this study to produce two separate control UHSC mixtures. The siliceous sand contained quartz $(64.0 \%)$, chert (17.1\%), and feldspar (11.5\%) and was procured from El Paso, TX. Previous research completed by Folliard et al. [13] showed this aggregate to be highly ASR reactive based on ASTM C1260 [14] and ASTM C1293 [15] test methods. The limestone aggregate was procured from within the central Texas region. The spent foundry sand (FS) was obtained from a local metal casting company. The sand is spent sand from molds used in their facility and is classified as a green sand (clay bonded system) [2]. Since the FS is unique and has prior processing, the chemical composition of the obtained FS was determined through X-ray fluorescence (XRF) and the results are shown in Table 2.

Based on a literature survey, it is recommended to only use fine aggregate in UHSC mixtures in order to increase the particle packing density and therefore increase strength [6]. It is specifically recommended to use fine aggregate passing ASTM number 30 sieve. Therefore, the two fine aggregates and FS were sieved and collected past the number 30 sieve. The grain size distribution for each aggregate can be seen in Table 3 while the physical properties are presented in Table 4. The specific gravity and densities were very close in value ranging within $2.43-2.62$ and $1,411-1,510 \mathrm{~kg} / \mathrm{m}^{3}$, respectively. However, the water absorption for the FS was very low compared to the control measuring only $0.08 \%$. 
TABLE 4: Physical properties of aggregates and foundry sand.

\begin{tabular}{lccccc}
\hline Property & Standard & Unit & Manufactured sand & Siliceous sand & Foundry sand \\
\hline Unit weight & ASTM C29 & $\mathrm{kg} / \mathrm{m}^{3}\left(\mathrm{lb} / \mathrm{ft}^{3}\right)$ & $1,432(89.4)$ & $1,510(94.3)$ & $1,411(88.0)$ \\
Water absorption & ASTM C127 & $\%$ & 1.94 & 0.99 & 0.08 \\
Bulk specific gravity $_{\text {ssd }}{ }^{\mathrm{a}}{ }^{\mathrm{b}}$ & ASTM C127 & - & 2.52 & 2.56 & 2.62 \\
Bulk specific gravity $_{\text {od }}$ & ASTM C127 & - & 2.43 & 2.52 & 2.62 \\
\hline
\end{tabular}

${ }^{a}$ ssd, saturated surface dry condition; ${ }^{\mathrm{b}}$ od, oven dried condition.

TABLE 5: Concrete mixture proportions.

\begin{tabular}{|c|c|c|c|c|c|c|c|c|}
\hline \multirow[t]{2}{*}{$\begin{array}{l}\text { Mixture } \\
\text { name }\end{array}$} & Cement & Silica fume & $\begin{array}{c}\text { Manufactured } \\
\text { sand }\end{array}$ & Reactive sand & Foundry sand & Steel fibers & HRWRA & Water \\
\hline & $\mathrm{kg} / \mathrm{m}^{3}\left(\mathrm{lb} / \mathrm{yd}^{3}\right)$ & $\mathrm{kg} / \mathrm{m}^{3}\left(\mathrm{lb} / \mathrm{yd}^{3}\right)$ & $\mathrm{kg} / \mathrm{m}^{3}\left(\mathrm{lb} / \mathrm{yd}^{3}\right)$ & $\mathrm{kg} / \mathrm{m}^{3}\left(\mathrm{lb} / \mathrm{yd}^{3}\right)$ & $\mathrm{kg} / \mathrm{m}^{3}\left(\mathrm{lb} / \mathrm{yd}^{3}\right)$ & $\mathrm{kg} / \mathrm{m}^{3}\left(\mathrm{lb} / \mathrm{yd}^{3}\right)$ & $1 / \mathrm{m}^{3}\left(\mathrm{gal} / \mathrm{yd}^{3}\right)$ & $\mathrm{kg} / \mathrm{m}^{3}\left(\mathrm{lb} / \mathrm{yd}^{3}\right)$ \\
\hline NR-Cont & $890(1500)$ & $222(375)$ & $821(1384)$ & - & - & $119(200)$ & $29.7(6)$ & $222(375)$ \\
\hline NR-10FS & $890(1500)$ & $222(375)$ & 739 (1246) & - & $90(152)$ & 119 (200) & $29.7(6)$ & $222(375)$ \\
\hline NR-20FS & $890(1500)$ & $222(375)$ & 657 (1108) & - & $180(303)$ & $119(200)$ & $29.7(6)$ & $222(375)$ \\
\hline NR-30FS & $890(1500)$ & $222(375)$ & $575(455)$ & - & $270(455)$ & $119(200)$ & $29.7(6)$ & $222(375)$ \\
\hline RA-Cont & $890(1500)$ & $222(375)$ & - & 842 (1419) & - & $119(200)$ & $29.7(6)$ & $222(375)$ \\
\hline RA-10FS & $890(1500)$ & $222(375)$ & - & 757 (1276) & $90(152)$ & $119(200)$ & $29.7(6)$ & $222(375)$ \\
\hline RA-20FS & $890(1500)$ & $222(375)$ & - & $673(1134)$ & $180(303)$ & $119(200)$ & $29.7(6)$ & $222(375)$ \\
\hline RA-30FS & $890(1500)$ & $222(375)$ & - & $589(992)$ & $270(455)$ & $119(200)$ & $29.7(6)$ & $222(375)$ \\
\hline
\end{tabular}

NR: nonreactive (manufactured sand); RA: reactive aggregate (siliceous sand); FS: foundry sand.

3.3. UHSC Mixtures. The concrete mixtures were developed based on the literature $[1,6,7]$. In these studies, UHSC mixtures incorporating high volumes of cement and silica fume, as well as finely graded natural sand, were produced. In this study, the final UHSC mix designs consisted of fine aggregate sieved and collected past the \#30 sieve $(<0.595$ $\mathrm{mm}[0.0234$-in]), OPC, silica fume, and steel fibers. The steel fibers are a common addition for providing additional ductility and fracture toughness in UHSC mixtures. Two series of UHSC mixtures utilizing both fine aggregates (designated as NR and RA for the nonreactive and reactive aggregates, resp.) were prepared at a water-cementitious ratio $(\mathrm{w} / \mathrm{cm})$ of 0.20 to monitor the impact of spent foundry sand on the hydration and alkali silica reactivity. Spent foundry sand, with a size of $<0.595-\mathrm{mm}$ [0.0234-in] to match the size of the virgin fine aggregates, was utilized at 10, 20, and $30 \%$ replacement by volume of fine aggregate, where the $100 \%$ virgin aggregate represented the control. A polycarboxylatebased HRWRA was used to achieve desired workability. The mixture proportions of the two mixtures including their 10,20 , and $30 \%$ foundry waste replacements are shown in Table 5.

3.4. Specimen Preparation. The aggregates used in this study were sieved to obtain the desired size needed as described previously. The aggregates were then thoroughly washed over a number 200 sieve to remove any fine dust or debris. After washing, the aggregates were oven-dried at $44^{\circ} \mathrm{C}\left(110^{\circ} \mathrm{F}\right)$ for a minimum of 24 hours to achieve a $0 \%$ moisture content.

The constituents of each mixture were then mixed for approximately 20 minutes using a laboratory pan mixer. The dry constituents (aggregate, cement, and silica fume) were mixed for the first 2 minutes and then $75 \%$ of the water was added. After thorough mixing, the HRWRA was added with the remaining $25 \%$ of the water. This preparation method was used based on the literature and experience $[1,6,7]$.

3.5. Curing Regimens. In order to minimize as many variables as possible, one curing regimen was tested for the compression testing samples, which was selected based on the literature review developed by Shaheen and Shrive [16]. This curing regimen consists first of curing the samples at room temperature $23^{\circ} \mathrm{C}\left(73^{\circ} \mathrm{F}\right)$ for the first 24 hours. After demolding, the specimens were then heat cured in a water bath at $50^{\circ} \mathrm{C}\left(122^{\circ} \mathrm{F}\right)$ until 2 days prior to testing. At two days prior to testing, the specimens were removed from the water bath and dry cured at $200^{\circ} \mathrm{C}\left(392^{\circ} \mathrm{F}\right)$. The dry curing was added based on recommendation from the literature review [16], such that a high dry curing 2 days prior to testing accelerates strength gain.

3.6. Compression Testing. Compressive strength specimens were molded using 50-mm (2-in.) cube molds. Cubes specimens were used to avoid problems with end preparation of cylindrical specimens [2]. After the specimens were properly cured, they were individually tested according to BS 12390-32009 [17]. The British Standard was used as it provides greater detail to testing hardened concrete cubes in compression than ASTM C 39-15a [17, 18]. An average of three samples was tested per data point reported in the Results.

3.7. Calorimetry. Mortar samples from each mixture were used to monitor the heat development using a Calmetrix 
isothermal calorimeter suitable for paste, mortar, and concrete samples. A standard $23^{\circ} \mathrm{C}$ isothermal temperature was used in this experimental program. Immediately after mixing, roughly 50 grams was weighed and placed in plastic cup molds designed specifically for use in the calorimeter. The average hydration curves of two samples from each batch were used and are presented in the Results.

3.8. Alkali Silica Reaction. The accelerated mortar bar method (AMBT) ASTM C1567 [19] was used for evaluating the potential reactivity of the aggregate in different foundry sand blends. However, modifications to the standard were used in this experimental program. The standard specifies a standard gradation for the fine aggregate and $\mathrm{w} / \mathrm{cm}$ ratio to be used during testing. In this program, mixtures were proportioned according to the details mentioned in Section 3.2 to achieve the UHSC requirement. The modifications to ASTM C1567 included using a lower water-cement (w/c) ratio and fine aggregate sieved and collected past the \#30 sieve $(<0.595$ $\mathrm{mm}[0.0234$-in]).

A minimum of four prisms $25 \times 25 \times 285-\mathrm{mm}[1 \times 1$ $\times 11.25$-in] were used to determine the change in length as outline in ASTM C1567 [19]. Immediately after casting, the molds were covered and placed in a moist curing room at $23^{\circ} \mathrm{C}$ for 24 hours. Thereafter, the bars were preconditioned for 24 hours in water maintained at $80 \pm 2^{\circ} \mathrm{C}$. The length of the mortar bars was measured, and then the bars were immediately transferred to storage filled with $1 \mathrm{~N} \mathrm{NaOH}$ solution maintained at $80^{\circ} \mathrm{C}$ for testing. The length of the prisms was periodically measured over a 28-day period instead of the normal 14-day period recommended in ASTM C1569 procedure as outlined by Thomas et al. [20]. This decision was made due to the unique mixture proportion nature of UHSC and the use of fibers, which Thomas et al. [20] do not have recommendations for; therefore measurements were taken over a longer period.

\section{Results and Discussion}

4.1. Strength Development. The compressive strengths for the UHSC mixtures with different percentages of spent foundry sand at 7, 14, and 28-day curing are shown in Figures 1 and 2 for the nonreactive and reactive aggregates, respectively.

The average control compressive strength for all ages was approximately $119 \mathrm{MPa}(17,300 \mathrm{psi})$, which is well above the minimum compressive strength threshold set for UHSC mixtures. This result demonstrates that, at minimum, a UHSC mixture was produced and the impact of FS replacement is investigated. The mixtures incorporating FS ultimately demonstrate a loss in compressive strength with an increase in FS percentage. At $10 \%$ inclusion of FS, the average compression strength for all ages dropped to approximately $107 \mathrm{MPa}(15,586 \mathrm{psi})$, which is approximately a $10 \%$ reduction in strength from the control. At a $20 \%$ fine aggregate replacement with FS, the average compressive strength for all ages dropped to approximately $102 \mathrm{MPa}(14,849 \mathrm{psi})$, which is a $15 \%$ drop in compressive strength when compared to the control. Lastly, at a $30 \%$ FS replacement level, the compressive strength dropped to approximately $96 \mathrm{MPa}(14,000 \mathrm{psi})$,

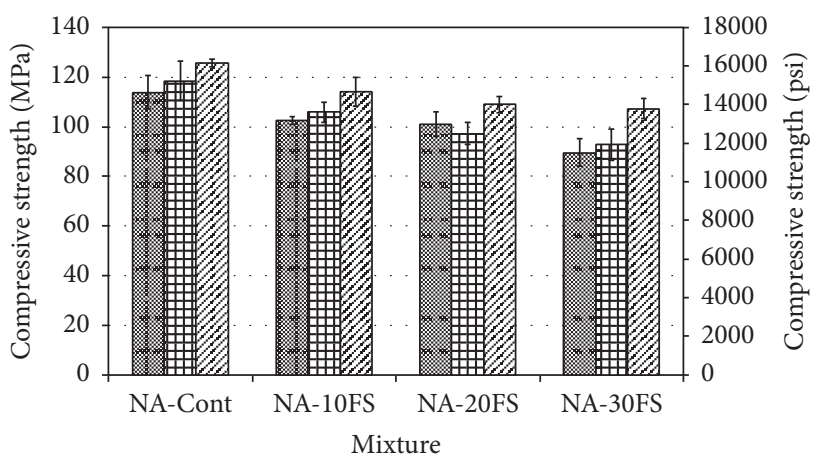

$$
\begin{aligned}
& 7 \text { days } \\
& \text { * } 14 \text { days } \\
& \square 28 \text { days }
\end{aligned}
$$

FIGURE 1: Compressive strength of manufactured (nonreactive) sand: foundry sand mixtures at 7,14 , and 28 days.

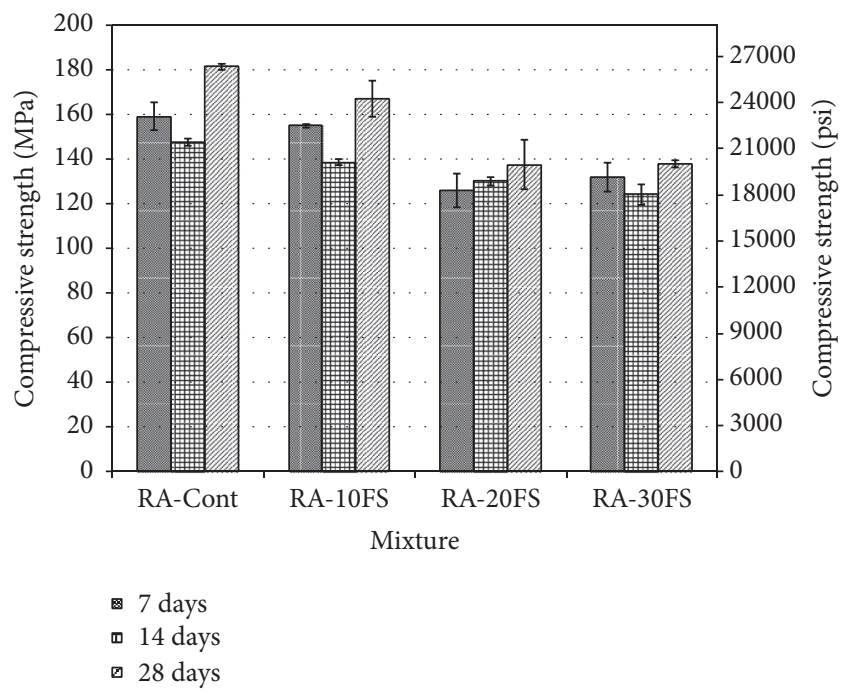

FIGURE 2: Compressive strength of reactive sand: foundry sand mixtures at 7, 14, and 28 days.

which is $21 \%$ loss in compressive strength when compared to the control samples. To confirm if these results are statistically significant, Student's $t$-test was completed. This statistical evaluation was performed at 95\% confidence interval and a statistical significance ( $p$ value) of 0.05 level of confidence. This analysis was completed comparing each FS replacement level to the control strength to determine if the noticed trend is significant. The statistical analysis shows that the $10 \%, 20 \%$, and $30 \%$ FS replacement mixtures are statistically significant with a $p$ value of $0.041,0.015$, and 0.005 , respectively. This result confirms that an increase in FS replacement, up to the $30 \%$ replacement level tested, yields a loss in compression strength. However, it should be noted that at the highest replacement level tested (30\%) the average compressive strength for all ages was still quite high (96 MPa (14,000 psi)) and still considered UHSC; therefore there is still application for this mixture, which is more sustainable than the control. Lastly, it should be noted that the nonreactive sand showed 
an increase in strength with age aside from the $20 \%$ FS replacement, which showed a drop in strength of approximately $4 \%$ from the 7 -day strength to the 14 -day strength; however, the 28-day strength remained the highest obtained strength. Although the average value of the NR-20FS was lowest at 14 days, this minor deviation from the overall trend is still within the standard deviation of the increasing strength with age trend of all other samples. Student's $t$-test was also performed on this value to further demonstrate that the 14-day strength (NR-20FS) value was not significant when compared to the 7-day strength (NR-20FS) with a $p$ value of 0.18 . Overall, the compression strength performance of the nonreactive (manufactured sand) demonstrated that all mixtures produced were of UHSC quality with varied degrees of strength and sustainability.

On the other hand, mixtures incorporating reactive siliceous sand showed substantially higher strength performance. The control mixture showed the highest compressive strength overall, exceeding $150 \mathrm{MPa}(21,755 \mathrm{psi})$ after only 7 days of curing. Interestingly, a sharp reduction in compressive strength was noted after 14 days of curing for all mixtures with the exception of $20 \%$ foundry sand. This may be attributed to the self-desiccation of the low $\mathrm{w} / \mathrm{cm}$ concrete mixture limiting the continued hydration for the additional formation of hydration product [21]. However, a notable change in the strength development after 28 days of heat curing was observed showing the highest compressive strength overall for all UHSC mixtures. Similarly to the mixtures incorporating the nonreactive manufactured limestone, a drop in compression strength was observed with increasing replacement of foundry sand. To determine if these results are statistically significant, Student's $t$-test was completed similarly as before. The statistical analysis shows that the 10\%,20\%, and 30\% FS replacement mixtures are statistically significant with a $p$ value of $0.045,0.027$, and 0.019 , respectively. The $t$-test confirms that there is a reduction in compressive strength relative to the control with increasing replacement of FS at up to $30 \%$ replacement.

The control mixture reached a compressive strength of $181.78 \mathrm{MPa}(26,365 \mathrm{psi})$, whereas mixtures RA-10FS, RA20FS, and RA-30FS observed a compressive strength of 167.21 (24,252 psi), $137.70(19,972 \mathrm{psi})$, and $137.90 \mathrm{MPa}(18,550.33)$, respectively. This is contrary to what previous studies have shown that spent foundry sand used as a partial replacement of fine aggregate can improve the mechanical properties of concrete $[2,3]$. However, these past studies limited their focus to normal-strength concrete. Thus, the results may indicate that the addition of foundry sand may contribute to additional imperfections between the paste-aggregate interphase and limiting the concrete's ability to achieve higher compressive strengths. Nonetheless, the compressive strength results between all the mixtures demonstrate that up to $30 \%$ of foundry waste can be used to replace the virgin fine aggregate while still exceeding the UHSC requirements $(\geq 70 \mathrm{MPa}(10,000 \mathrm{psi}))[1]$.

4.2. Alkali Silica Reactivity. The potentials for alkali silica reactivity for both the nonreactive and reactive aggregates containing foundry sand are presented in Figures 3 and 4.

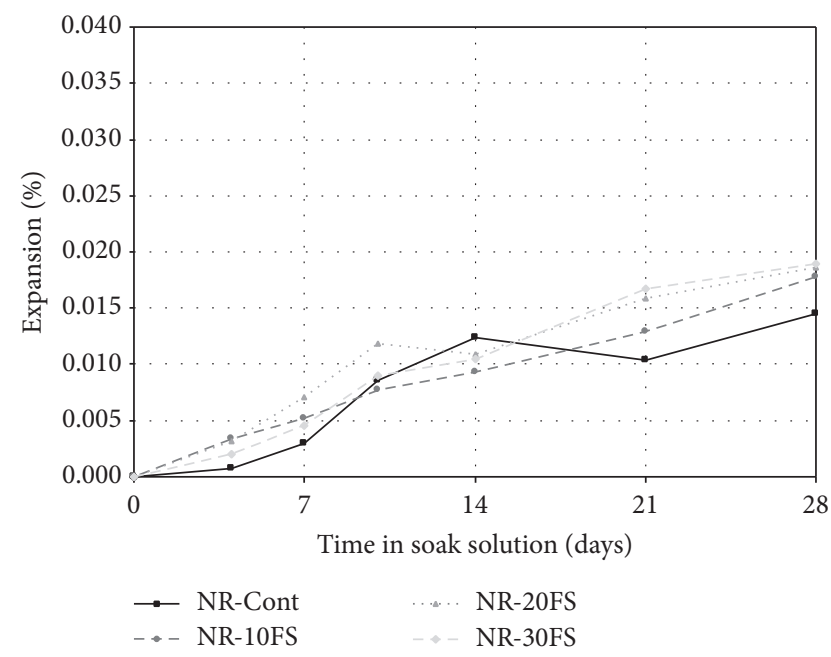

FIGURE 3: Expansion curves of manufactured (nonreactive) sand: foundry sand mixtures.

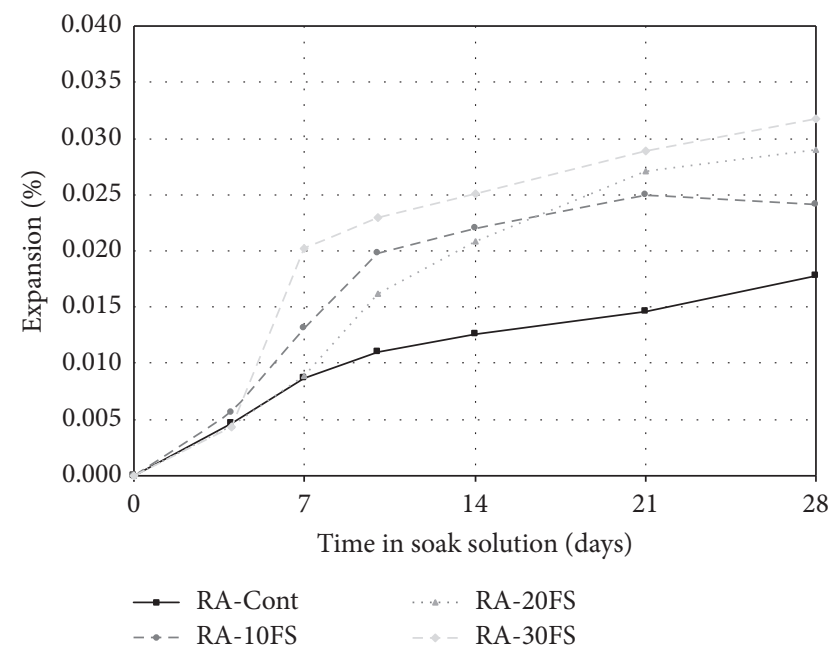

FIgURE 4: Expansion curves of reactive sand: foundry sand mixtures.

After 28-day storage in $\mathrm{NaOH}$ solution, mixtures containing foundry sand showed a slight increase in expansion compared to their control, although the final expansion value between the two aggregates is not very remarkable. The results indicate that as higher replacements of foundry sand are incorporated into the mixture, expansion of the prisms is also higher. The effects are pronounced for those mixtures utilizing the reactive siliceous aggregate. This may be attributed to the additional silica content coming from the foundry sand waste [22].

Note that the prisms were cast using high capacity steel fibers as a part of the matrix. Thus, only minor changes in length were observed for both series of mixtures and well under the expansion limit of $0.10 \%$ for deleterious alkali silica reactivity as suggested by $[23,24]$. As discussed previously, the steel fibers provide extra restraint against tensile stresses and thus contributed to reduced expansion observed in the prisms. However, cracking was still apparent surrounding 


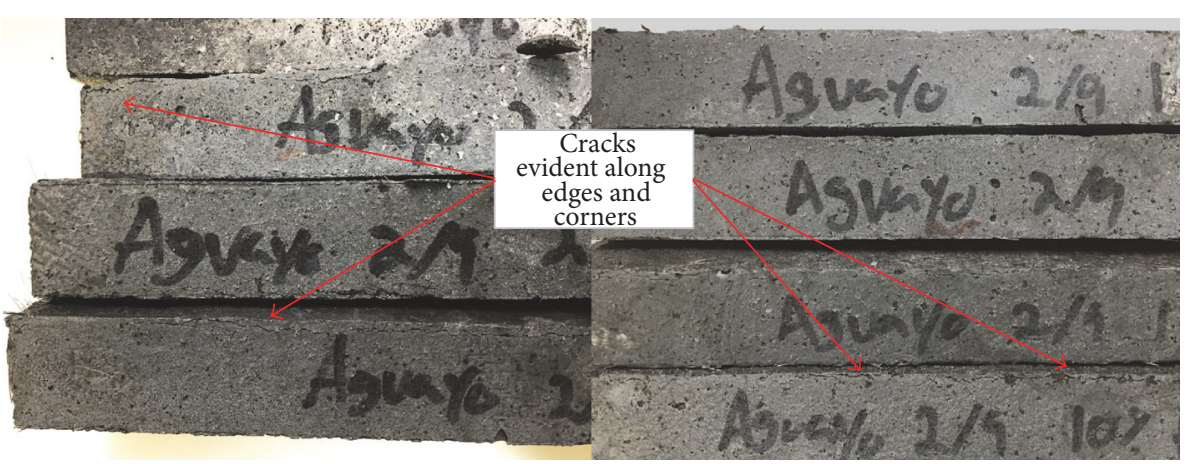

(a)

(b)

FIGURE 5: Cracking of reactive bars observed after 28 days in $\mathrm{NaOH}$ solution: (a) RA-30FS; (b) RA-10FS.

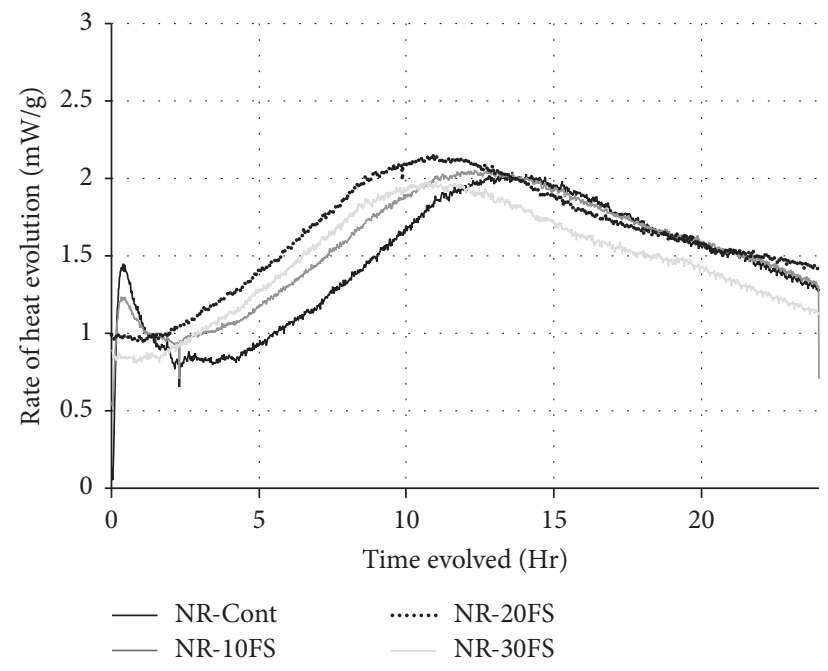

FIGURE 6: Heat flow curves for UHSC-FS mixtures using nonreactive aggregate.

the edges of the prisms for the mixtures incorporating the reactive aggregate (see Figure 5) indicating there still exists a large potential for ASR reactivity.

4.3. Heat of Hydration. Isothermal calorimetry was chosen as the method for investigating the hydration of UHSC mixtures with various replacement of foundry waste. Isothermal calorimetry measures the heat flow from cement hydration reactions by differential heat flow sensors that allow for comparison of different mixtures and provide a time-lapsed understanding of the hydration mechanisms. The timing and shape of heat flow curves can provide an understanding of the performance of different cementitious systems. Additionally, heat flow curves combined with compressive strength data can provide insight on the mechanisms through which the addition of mineral admixtures such as foundry waste influences strength development.

The data from isothermal calorimetry test were used to plot curves showing the rate of heat produced during hydration and are presented in Figures 6 and 7 for the nonreactive and reactive sand, respectively. A summary of

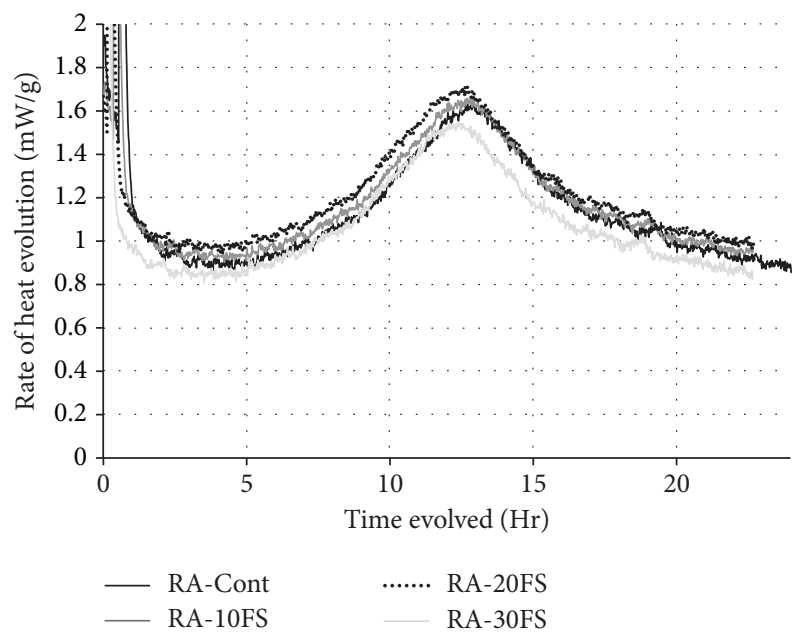

FIGURE 7: Heat flow curves for UHSC-FS mixtures using reactive aggregate.

the peak heat flow for each mixture compared to that of the control is also listed in Table 6. Each heat flow curve has been normalized to the amount of cement in the mortar (i.e., 50gram mortar sample). The shape and position of the heat flow curves for the foundry waste UHSC mixtures relative to the curve of the control provide valuable information regarding the effect of the foundry waste on cement hydration. A leftward shift of the heat flow curve relative to the control curve indicates an advancement in the onset of cement hydration which in turn suggests an acceleration of cement hydration kinetics. From Figure 6, it can be observed that the rate of heat curve for the foundry waste UHSC mixtures using nonreactive aggregate shifted significantly to the left of the control curve. On the other hand, the rate of heat curves for similar mixtures using reactive aggregate did not show a significant deviation to the left of the control curve. In fact, mixture RA-10FS showed slight delay in activity with a slight shift to the right from the control (see Table 6). The increase activity from the addition foundry waste is most likely attributed to additional nucleation sites and increased reactivity of hydration products, or the "size filler effect" 
TABLE 6: Heat of hydration summary for concrete mixtures.

\begin{tabular}{lcccc}
\hline Mix-ID & $\begin{array}{c}\text { Avg. peak heat flow } \\
(\mathrm{mW} / \mathrm{g} \text { cement })\end{array}$ & $\begin{array}{c}\text { Deviation from control sample } \\
(\mathrm{mW} / \mathrm{g} \text { cement })\end{array}$ & $\begin{array}{c}\text { Avg. time until peak heat flow } \\
(\mathrm{Hr})\end{array}$ & $\begin{array}{c}\text { Deviation from control sample } \\
(\mathrm{Hr})\end{array}$ \\
\hline NR-Cont & 2.04 & - & 13.58 & - \\
NR-10FS & 2.06 & 0.02 & 12.30 & 1.28 \\
NR-20FS & 2.15 & 0.11 & 10.92 & 2.67 \\
NR-30FS & 1.98 & -0.06 & 10.77 & 2.82 \\
RA-Cont & 1.64 & - & 12.65 & - \\
RA-10FS & 1.66 & 0.03 & 12.90 & -0.25 \\
RA-20FS & 1.71 & 0.07 & 12.63 & 0.02 \\
RA-30FS & 1.55 & -0.09 & 12.40 & 0.25 \\
\hline
\end{tabular}

[25-27]. The finer particle distribution of the foundry waste compared to that of the reactive sand (see Table 3 ) provided a better particle packing of materials. This may have resulted in an increase in the number of foundry sand particles available per grain of cement for nucleation and increased hydration reactivity. For the foundry waste UHSC mixtures using nonreactive sand, the average deviation in time to reach the peak heat flow was $1.28,2.67$, and 2.82 hours relative to the control, which is approximately a $9.4 \%, 19.6 \%$, and $20.7 \%$ reduction for $10 \%, 20 \%$, and $30 \%$ foundry waste replacement, respectively. For the equivalent mixtures using reactive siliceous sand, the deviation in time to reach the peak heat flow was $-0.25,0.02$, and 0.25 hours relative to their control, which is approximately a $2.0 \%$ increase and $0.0016 \%$ and $2 \%$ reduction for $10 \%, 20 \%$, and $30 \%$ foundry waste replacement, respectively. Note that a negative sign indicates a delay in hydration reactivity (rightward shift) relative to the control and vice versa for a positive value.

From Figures 6 and 7 and Table 6, it can be observed that the average measured peak heat flow between each foundry waste replacement relative to their control did not show a significant deviation. However, there was some notable differences in the peak heat flow between the two aggregate types (see Table 6). On average, mixtures using the nonreactive (manufactured) sand exhibited a 24.4\%, 24.1\%, 25.7\%, and $27.7 \%$ increase in average peak heat flow for the control, $10 \%, 20 \%$, and $30 \%$ foundry waste replacement compared to the reactive sand mixtures, respectively. This suggests that the foundry waste UHSC mixtures containing nonreactive aggregate, which has a similar particle size distribution to the foundry waste, exhibited enhanced nucleation and growth of hydration products, whereas the size filler effects are minimal in the mixtures containing reactive aggregate. Interestingly, the measured compressive strength between the two aggregate types also observed apparent differences. Note that all mixtures used equivalent cementitious contents and only the influence of foundry waste was investigated in this study.

\section{Conclusions}

A sustainable, high strength concrete mixture using waste foundry sand was investigated in this study. Mechanical properties, hydration reactivity, and alkali silica reactivity were monitored on two series of UHSC mixtures blended with spent foundry sand up to $30 \%$ replacement of fine aggregate by volume. Based on the investigation, the following conclusions can be drawn:

(i) For both series of UHSC mixtures using nonreactive and reactive fine aggregate, a decrease in compressive strength was observed with the replacement of natural fine aggregate with that of foundry waste up to the $30 \%$ replacement investigated.

(ii) UHSC mixtures using the reactive siliceous sand yielded the highest compressive strengths compared to those using the nonreactive manufactured sand. However, the minimum compressive strength observed was $85 \mathrm{MPa}(12,345 \mathrm{psi})$ at the highest replacement level tested (30\%) for the series of mixtures using nonreactive sand and is still considered UHSC.

(iii) The alkali silica reactivity for mixtures containing foundry sand showed an increase in expansion with increasing replacement of foundry waste up to $30 \%$. The effects are pronounced for those mixtures blended with foundry waste and reactive siliceous aggregate.

(iv) The calorimetry data showed that the addition of foundry waste enhanced the growth of hydration products by providing extra nucleation and growth sites with their finer particle size distribution. This was very pronounced for the UHSC mixtures using nonreactive fine aggregate.

\section{Acronyms}

ACI: American Concrete Institute

ASTM: American Society for Testing and Materials

ASR: Alkali silica reaction

AMBT: Accelerated mortar bar test

CIM: Concrete Industry Management

FS: $\quad$ Foundry sand

GGBFS: Granulated ground blast furnace slag

HRWRA: High range water reducing admixture

NR: $\quad$ Nonreactive

OD: Oven dry 
OPC: Ordinary Portland cement

RA: Reactive aggregate

REP: Research Enhancement Program

SCM: Supplementary cementitious material

SSD: $\quad$ Saturated surface dry

UHSC: Ultrahigh strength concrete

XRF: X-ray fluorescence.

\section{Conflicts of Interest}

The authors declare that there are no conflicts of interest regarding the publication of this paper.

\section{Acknowledgments}

The authors of this study would like to thank Research Enhancement Program (REP) at Texas State University for the support of this research. The authors would also like to thank Mr. Brady Gillar from Southwest Steel Casting Company for donating the foundry waste to their study. Lastly, thanks are due to the several undergraduate researchers in the Concrete Industry Management (CIM) program for their assistance in this work.

\section{References}

[1] ACI Committee 363, "Report on High-Strength Concrete," Tech. Rep., American Concrete Institute Committee 363, Farmington Hills, Mich, USA, 2010.

[2] R. Siddique, G. D. Schutter, and A. Noumowe, "Effect of used-foundry sand on the mechanical properties of concrete," Construction and Building Materials, vol. 23, no. 2, pp. 976-980, 2009.

[3] R. Siddique and A. Noumowe, "Utilization of spent foundry sand in controlled low-strength materials and concrete," Resources, Conservation and Recycling, vol. 53, no. 1-2, pp. 2735, 2008.

[4] T. Abichou, C. Benson, and T. Edil, "Database on beneficial reuse of foundry by-products," in Geotechnical Special Publication No. 79. ASCE, C. Vipulanandan and D. Elton, Eds., Recycled Materials in Geotechnical Applications, pp. 210-223, American Society of Civil Engineers, 1998.

[5] Ministry Of Electricity \& Renewable Energy, "Spent foundry sand: alternative uses study," report prepared by john emery geotechnical engineering limited for ontario ministry of the environment and energy and the Canadian foundry association, Queen's Printer for Ontario, 1993.

[6] S. Collepardi, L. Coppola, R. Toli, and M. Colepardi, "Mechanical properties of modified reactive powder cocnrete," Mechanical Properties of Modified Reactive Powder Cocnrete, 2007.

[7] A. S. Dili and M. Santhanam, "Investigations on reactive powder concrete: A developing ultra high-strength technology," Indian Concrete Journal, vol. 78, no. 4, pp. 33-38, 2004.

[8] S. Fiore and M. C. Zanetti, "Foundry wastes reuse and recycling in concrete production," American Journal of Environmental Sciences, vol. 3, no. 3, pp. 135-142, 2007.

[9] G. Ganesh Prabhu, J. W. Bang, B. J. Lee, J. H. Hyun, and Y. Y. Kim, "Mechanical and durability properties of concrete made with used foundry sand as fine aggregate," Advances in Materials Science and Engineering, vol. 2015, Article ID 161753, 2015.
[10] Mohammed Viquaruddin and Abdullah Mohammed, "An Experimental Study on Mechanical Properties of Concrete Incorporating Foundry Sand," International Journal of Engineering Research and, vol. V6, no. 3, pp. 83-88, 2017.

[11] "Standard Specification for Portland Cement ASTM International," ASTM Standard C150/C150M-15 (2015), West Conshohocken, Pa, USA, 2015, https://www.astm.org.

[12] "Standard Specification for Silica Fume Used in Cementitious Mixtures ASTM International," ASTM Standard C1240/C618M15 (2015), West Conshohocken, Pa, USA, 2015, https://www.astm .org.

[13] K. Folliard, R. Barborak, T. Drimalas et al., "Preventing ASR/ DEF in new concrete: final report," Report No. FHWA/TX-060-4085-5, 2006.

[14] "Standard Specification for Potential Alkali Reactivity of Aggregates (Mortar-Bar Method," in Proceedings of the ASTM Standard C1260/C1260M-14 (2014) Standard Specification for Potential Alkali Reactivity of Aggregates (Mortar-Bar Method) ASTM International, vol. C1260/C1260M-14, pp. 10-1520, West Conshohocken, Pa, USA, 2014, https://www.astm.org.

[15] "Standard Specification for Determination of Length Change of Concrete Due to Alkali-Silica Reaction ASTM International," ASTM Standard C1293/C1293M-15 (2008), West Conshohocken, Pa, USA, 2015, https://www.astm.org.

[16] E. Shaheen and N. G. Shrive, "Optimization of mechanical properties and durability of reactive powder concrete," $A C I$ Materials Journal, vol. 103, no. 6, pp. 444-451, 2006.

[17] "Testing hardened concrete compressive strength of test specimens B/517/1," British Standard Institution BS EN 12390-3-2009, pg 22.

[18] "Standard Test Method for Compressive Strength of Cylindrical Concrete Specimens ASTM International," ASTM Standard C 39-15a (2015), West Conshohocken, Pa, USA, 2015, https://www .astm.org.

[19] "Standard Test Method for Determining the Potential AlkaliSilica Reactivity of Combination of Cementitious Materials and Aggregte (Accelerated Mortar-Bar Method) ASTM International," ASTM Standard C1567/C1567M-13 (2013), West Conshohocken, Pa, USA, 2015, https://www.astm.org.

[20] M. D. A. Thomas, B. Fournier, K. J. Folliard, M. H. Shehata, J. H. Ideker, and C. Rogers, "Performance limits for evaluating supplementary cementing materials usina accelerated mortar bar test," ACI Materials Journal, vol. 104, no. 2, pp. 115-122, 2007.

[21] M. A. Caldarone, High-strength Concrete: A Practical Guide, Taylor \& Francis, 1st edition, 2009.

[22] M. K. Dash, S. K. Patro, and A. K. Rath, "Sustainable use of industrial-waste as partial replacement of fine aggregate for preparation of concrete: a review," International Journal of Sustainable Built Environment, vol. 5, no. 2, pp. 484-516, 2016.

[23] M.-A. Berube, J. Duchesne, and D. Chouinard, "Why the accelerated mortar bar method ASTM C 1260 is reliable for evaluating the effectiveness of supplementary cementing materials in suppressing expansion due to alkali-silica reactivity," Cement, Concrete and Aggregates, vol. 17, no. 1, pp. 26-33, 1995.

[24] M. D. A. Thomas and F. A. Innis, "Use of the accelerated mortar bar test for evaluating the efficacy of mineral admixtures for controlling expansion due to alkali-silica reaction," Cement, Concrete and Aggregates, vol. 21, no. 2, pp. 157-164, 1999.

[25] C. Gosselin, "Microstructure development of calcium aluminate cements accelerated by lithium sulphate," in Proceedings of the Centenary Conference, pp. 109-122, HIS BRE Press, Avignon, France, 2008. 
[26] A. F. Bentivegna, Multi-Scale Characterization, Implementation, and Monitoring of Calcium Aluminate Cement Based-Systems [Ph.D. thesis], University of Texas, Dissertation Austin, Tex, USA, 2011.

[27] S. Seraj, Evaluating Natural Pozzolans for Use as an Alternative Supplementary Cementitious Materials in Concrete [Ph.D. thesis], University of Texas, Dissertation Austin, Tex, USA, 2014. 

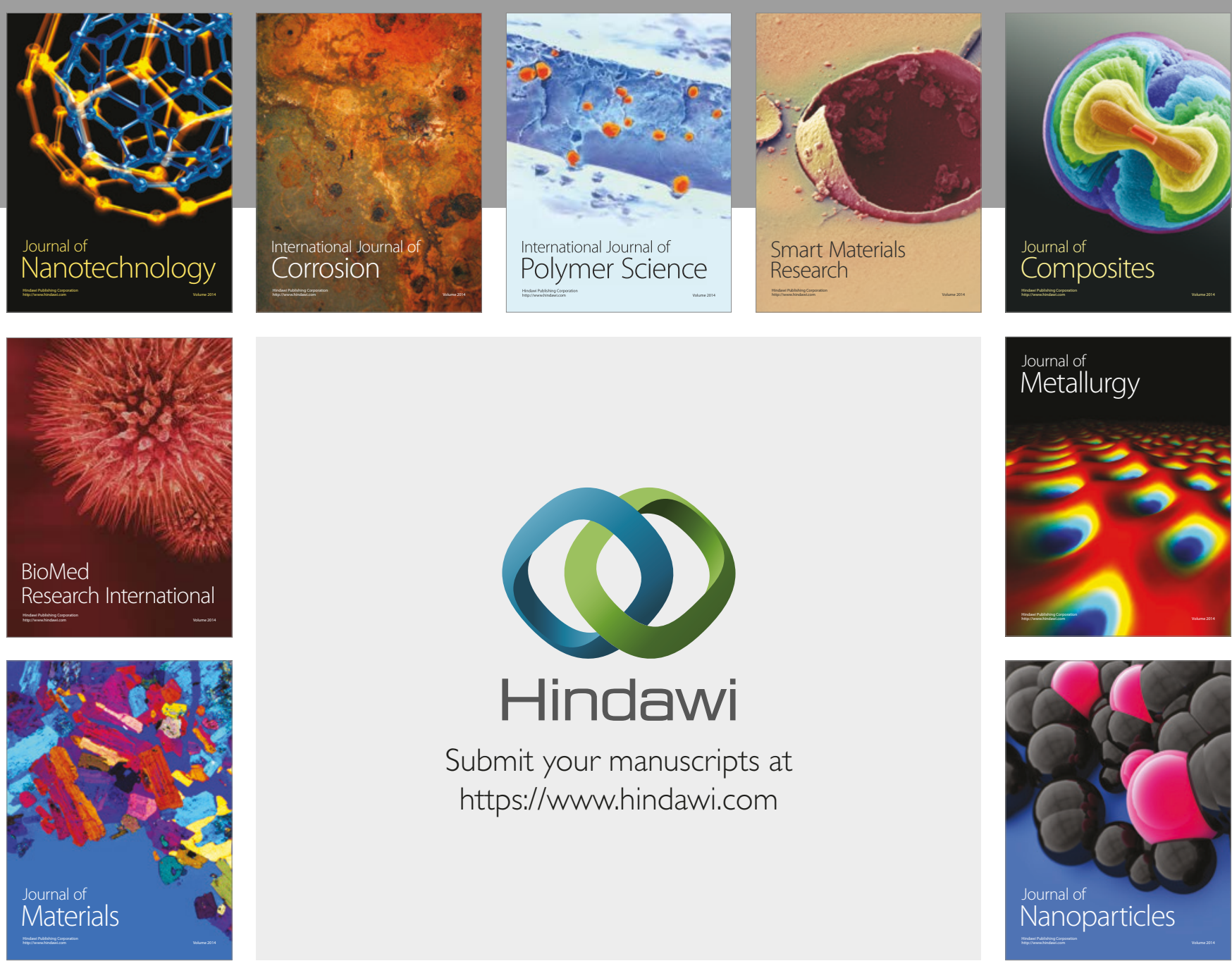

\section{Hindawi}

Submit your manuscripts at

https://www.hindawi.com
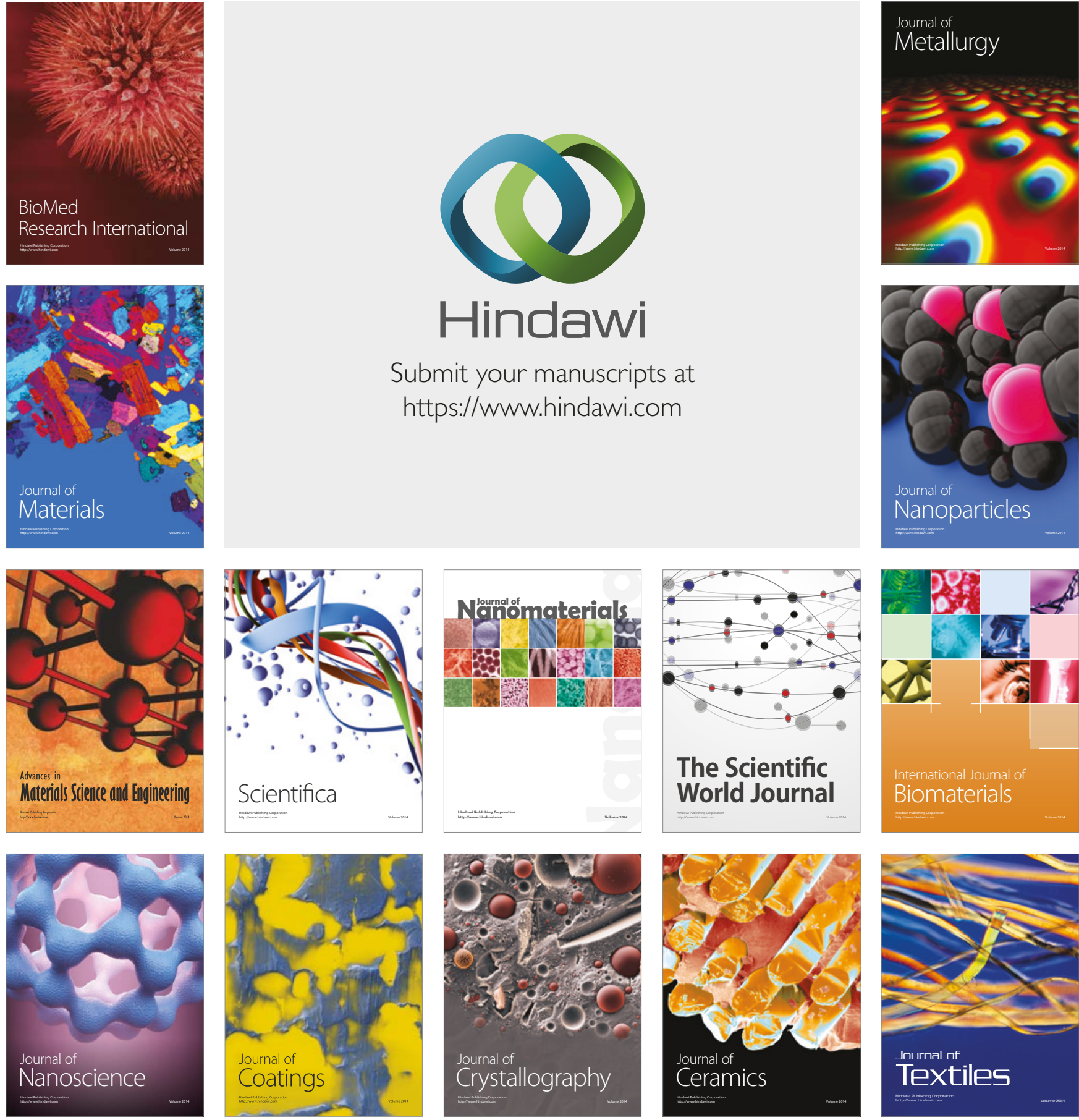

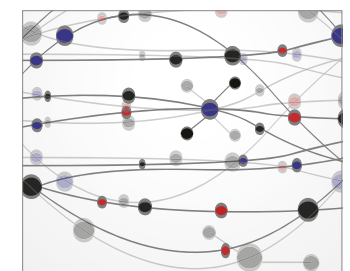

The Scientific World Journal
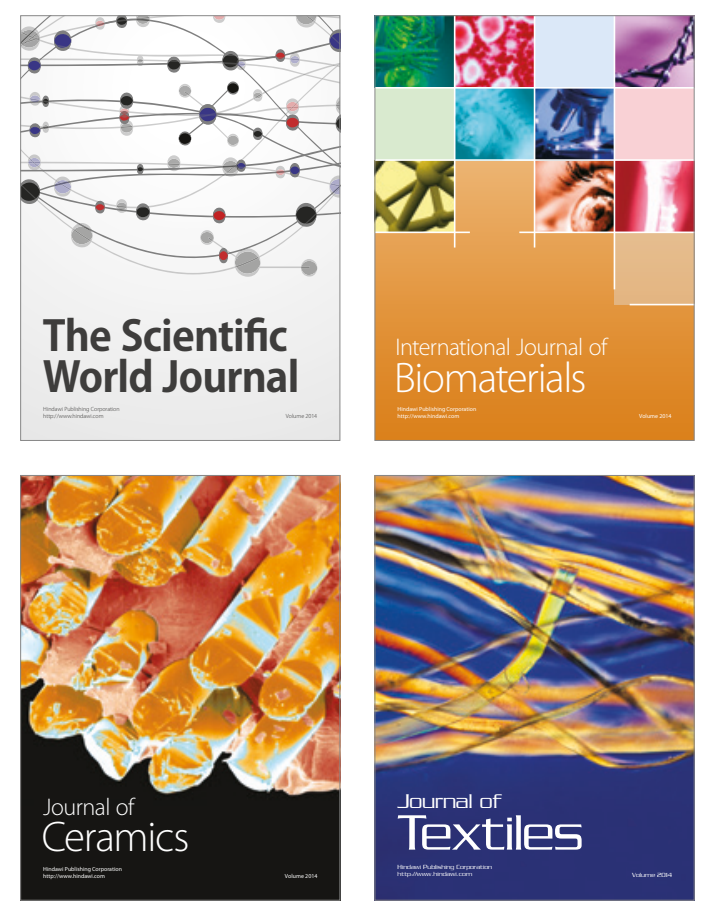